Original Article

\title{
Process evaluation of Village Health and Nutrition Day observation (VHND) in a block of Dibrugarh District of Assam
}

\author{
Tulika Goswami Mahanta ${ }^{a, *}$, Manjit Baruah ${ }^{b}$, \\ Bhupendra Narayan Mahanta ${ }^{c}$, Pranab Gogoi ${ }^{b}$, \\ Jenita Baruah ${ }^{b}$, Sachin Gupte ${ }^{d}$ \\ ${ }^{a}$ Associate Professor, Department of Community Medicine, Assam Medical College, Dibrugarh 786001, India \\ ${ }^{\mathrm{b}}$ Department of Community Medicine, Assam Medical College, Dibrugarh 786001, India \\ ${ }^{c}$ Associate Professor, Department of Medicine, Assam Medical College, Dibrugarh 786001, India \\ ${ }^{\mathrm{d}}$ Health Specialist, UNICEF, Assam, India
}

\section{A R T I C L E I N F O}

Article history:

Received 27 April 2014

Accepted 7 July 2014

Available online 4 August 2014

\section{Keywords:}

Village Health and Nutrition Day

(VHND)

National Rural Health Mission

(NRHM)

Dibrugarh

Assam

Client satisfaction

\begin{abstract}
A B S T R A C T
Problem considered: VHND, celebrated as a part of NRHM flagship program of GOI for better convergence of various services and community participation to develop community ownership. Improving the performance of frontline health workers is critical to enhance the coverage and delivery of quality health service.

Objectives: To assess and compare, service provision and client satisfaction of VHNDs.

Methods: A cross sectional before - after study, conducted in Lahuwal block, which is a tea tribe dominated block with less service access. All planned VHNDs of the block, assessed. Qualitative assessment was done using clients satisfaction format and in-depth interview of service providers. Capacity building, microplan development, setting up of minimum service delivery standards and monitoring and supervision mechanism was established. Comparison was done using Chi-square test.

Results: A total of 53 sessions were observed and reassessed after three months of program implementation and 253 respondents were exit interviewed. Significant improvement was observed in PNC $41.7 \%$ vs $90.9 \%$, ( $p=0.000$ ), FP counselling $22.2 \%$ vs $45.5 \%$ ( $p=0.037$ ), NHED $64.4 \%$ vs $91.7 \%$ ( $p=0.000)$, IFA supplementation $41.4 \%$ vs $58.6 \%(p=0.016)$, deworming 9.35 vs $34.7 \%(p=0.000)$ and counselling on specific health problem $25.3 \%$ vs $43.5 \%(p=0.008)$. Growth monitoring improved from $84.1 \%$ to $95.1 \%(p=0.058)$. Knowledge gain following capacity building was $19.67 \%$. Client satisfaction for quality of service improved from $96.7 \%$ to $98.6 \%$. Service providers informed the need for more involvement of PRI members and uninterrupted supply chain.

Conclusion: Improvement of service provision and client satisfaction could be achieved by better service delivery.
\end{abstract}

(C) 2014 INDIACLEN. Published by Elsevier B.V. All rights reserved.

\footnotetext{
* Corresponding author. Tel.: +91 9435032539 (mobile).

E-mail addresses: drtulikagoswami@gmail.com, tulika_gm@rediffmail.com (T.G. Mahanta). http://dx.doi.org/10.1016/j.cegh.2014.07.001

2213-3984/C 2014 INDIACLEN. Published by Elsevier B.V. All rights reserved.
} 


\section{Introduction}

Health and nutrition go hand in hand, thus the concept of conducting Village Health and Nutrition Day is a very promising strategy for achieving better health through increased focus on nutritional behaviour of the people in the community. The task of inter-departmental convergence, i.e. between health and ICDS departments, and consequently improved coverage of Maternal and child health services is however a complex task and needs detailed micro-planning as well. But VHND sessions have been adopted by many states and therefore different projects are being run in these states for improving the service delivery. ${ }^{1}$ Government of Assam has also adopted the concept and guidelines have been issued regarding the planning and conduct of the sessions. ${ }^{2}$ The VHND can be successfully used as a platform for providing first-contact primary health care in this state, as evidence is growing that primary care strategies centred on community based interventions are effective in reducing neonatal and maternal deaths in countries with high mortality rates, even if institutional approaches are necessary to reduce them further. ${ }^{3}$ It can thus also be seen as an interface for interaction between the community and the health system. The session is organized once every month (preferably on Wednesdays and for those villages that have been left out, on any other day of the same month) at the AWC in the village. This has been planned so as to ensure uniformity in organizing the VHND. VHND if organized regularly and effectively can bring about the much needed behavioural changes in the community, and can also induce health-seeking behaviour in the community leading to better health outcomes. ${ }^{4}$

Improving the performance of frontline health workers is critical to enhance the coverage and delivery of quality health services. In the community, the ASHAs, AWWs, and ANMs have the most direct link with mothers, new-born child, children, adolescents, and families. They can offer a wide range of information and services covering all maternal and child health programs under the NRHM umbrella and VHND is the platform to disseminate such information effectively. The aim of the VHND is to create awareness about various health facilities available at village and subsequent levels, enhancing healthy behaviour practices among villagers and providing nutrition and primary health care services for women and children especially to marginalized and vulnerable communities; that will improve the health and nutrition indicators of the state.

Assam has the highest MMR of 328 maternal deaths per 100,000 live births (SRS 2010-12) in India. Among the districts of Assam, highest maternal deaths occur in the districts of Upper Assam Division (MMR of 404/1lakh live births) of which Dibrugarh district is a part (AHS 2012-13). Most of the tea gardens are located in the Upper Assam Division. IMR of Assam 55/1000 LB is higher than the national average of 42/1000 LB (SRS 2013). In Dibrugarh district IMR is 51/1000 LB (AHS 2012-13). Prevalence of under nutrition and anaemia is very high especially amongst tea garden population. Several studies done with UNICEF support have shown 30-40\% prevalence of under nutrition amongst different age groups and $80-96 \%$ prevalence of anaemia amongst children, adolescent and adult population living in tea estates. High prevalence of common infections like Diarrhoea, and helminthic infestations indicates compromised water and sanitation facilities amongst population living in rural areas and tea gardens. There was evidence that lack of awareness about health, nutrition, hygiene and sanitation is responsible for such poor outcome. Therefore, the present study was conducted to evaluate the process of VHND implementation and in Lahuwal Block of Dibrugarh district and to identify the gaps in service provision on Village Health and Nutrition Day, if any. The study also aimed to provide technical input \& suggestions which can help strengthen the existing VHND strategy.

\section{Materials and methods}

\subsection{Setting}

Lahowal Block is situated at the middle of Dibrugarh District on the southern bank of the river Brahmaputra. The population of the block was 153,202 . The gender ratio in the Block is 931 females against 1000 males. The density of population is about 351/sq. km. A total of 141 villages and 28 tea estates were served by 35 subcentres (for health related services) and 127 numbers of Anganwadi workers (for nutrition related services). There are 6 numbers of main riverine areas (char areas) of the Brahmaputra river under Lahowal PHC; which are inaccessible.

Ethical clearance was taken from institutional ethical committee and human subject recruitment was done after that. Informed consent was taken for each participant and those not consenting were not included in the study.

\subsection{Sampling methods}

As there are three sub-divisions in the block, a plan was made to cover all sub-divisions equally in both quantitative and qualitative assessment. Before after intervention study was conducted covering all sessions held during the assessment period. Intervention was given in the form of capacity building, microplan development, setting up of minimum service delivery standards and monitoring and supervision mechanism was established. Reassessment was done three months after capacity building and monitoring and supportive supervision.

\subsection{Study procedure}

The VHNDs were observed by using a supervisory checklist (adopting standard format for monitoring developed by Government of India) introduced for exit interview and indepth schedule for observation of VHND sites. Exit interview of the clients, coming out of the VHND was carried out, for assessing the client satisfaction about the services and to track the services that they had received. Besides, this also gave an impression of the degree of awareness about VHND and its services amongst the clients. In each VHND which was observed, 4-5 exit interviews of different clients were taken. 


\subsection{Statistical analysis}

The data or information collected was compiled using SPSS v.17 software, chi-square test is used to compare the difference in proportion.

\section{Results}

All sessions held during the study period was assessed and 253 exit interviews could be carried out with a response rate of 95\%. Sessions were held as per microplan in 51 (96.2\%) before and in 52 (97.4\%) after capacity building and monitoring and supportive supervision. Antenatal check-up by ANM increased from $75.5 \%$ (40) to $86.8 \%$ (46) after the program intervention, discussion on sanitation increased after model VHND initiatives and counselling on hand washing, toilet use and water purification also showed improvement [Chart 1]. Availability of essential drugs and other logistics necessary for conducting VHND also showed improvement [Chart 2].

\subsection{Exit interview results}

A total of 53 sessions were observed initially and then reassessed after three month of program implementation. Around 253 respondents were interviewed, 179 before capacity building and 74 after capacity building workshop. Likert scale was used for interpretation of exit interviews.

The Mean age of clients attending the sessions was 25.40 years $(n=179, \mathrm{SD}=4.7)$ before training and after training it was almost same 25.62 years $(n=74, \mathrm{SD}=4.1)$. This indicated that a similar group of population was coming for availing services. $162(64.0 \%)$ of the exit interviews conducted were at an Anganwadi centre, 77 (30.4\%) were observed at a sub center and $14(5.5 \%)$ at tea garden hospital. Out of the total respondents interviewed, 103 (40.7\%) were pregnant mothers and 90 (35.6\%) were lactating mothers with child less than 6 months. But service usage by mothers with child 6 months -5 years drops down to $60(23.7 \%)$ as compared to mothers with below 6 months infants indicating that the sessions were being visited mostly for the purpose of immunization of the child [Table 1]. There was some improvement in visit of pregnant women and children between 6 months and five year. 151 (59.7\%) of the clients had to travel less than $0.5 \mathrm{~km}$ to reach the session site. On an average, mothers had to stay for $1.5 \mathrm{~h}$ to get the services provided. ASHA (Accredited social health activist), AWW (Anganwadi worker) and AWH (Anganwadi helper) were the source of information regarding sessions for 209 (82.6\%), 34 (13.4\%) and 10 (4.0\%) respondents respectively. Out of the total respondents interviewed, 200 (79.1\%) found it convenient to have all the services on the same day for them.

$\square$ After $\square$ Before

Counseling given on household purification of water Counseling for use of latrines being conducted Hand washing being demonstrated B.P. records maintenance Counseling done MCB Cards available IFA tablets provided TT available Ante Natal Check up Assistance by VHSNC member Identified malnourish child Nutritional advises provided Children weight taken Hub cutter available Drop out and left out list $0.1 \mathrm{ml}$ AD syringe $0.5 \mathrm{ml}$ AD syringes VVM on OPV

Are All vaccines available Banner and poster is displayed Session Held as per Micro plan

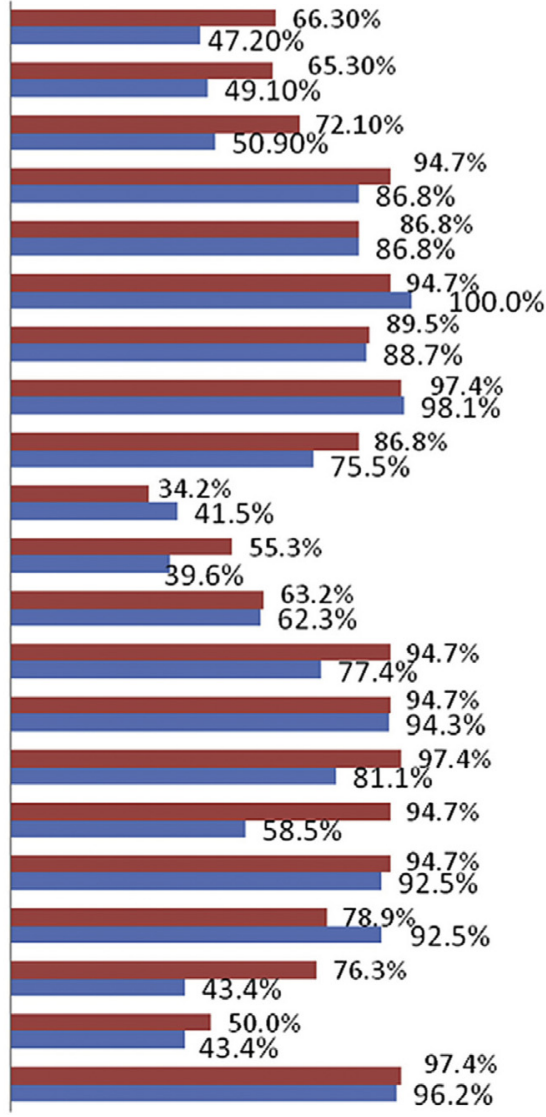




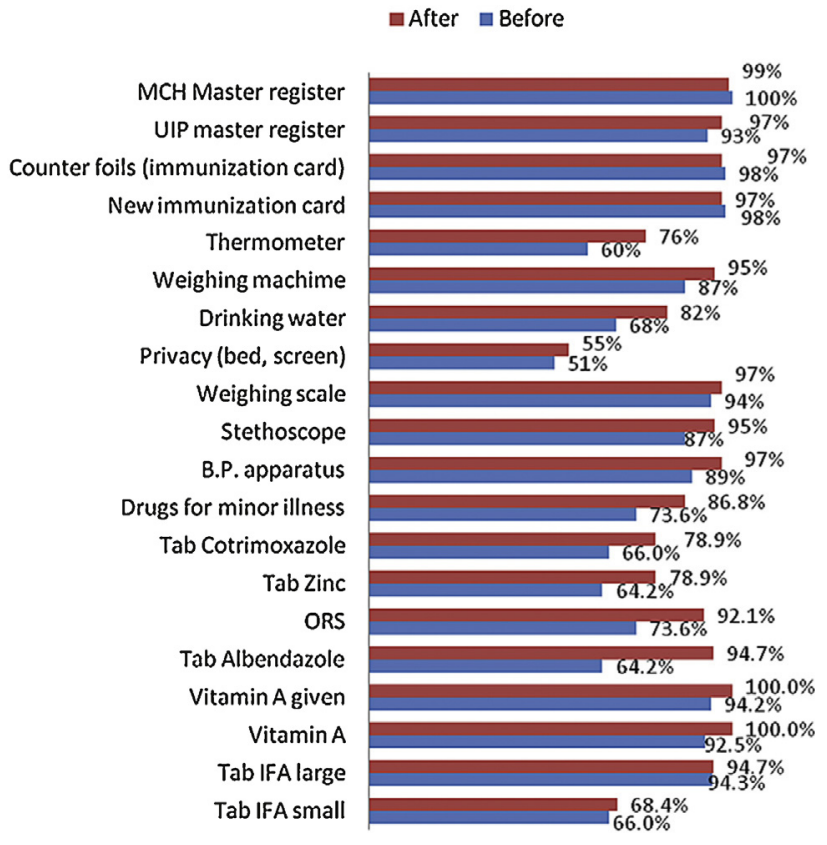

Chart 2 - Availability of Drugs and other logistics before and after capacity building.

Most of the clients were either moderately or highly satisfied with the quality of services provided by the frontline workers. And after training satisfaction level with the behaviour of the service provider improved significantly [Table 2]. Improvement in satisfaction level in post training period was documented amongst all categories of workers: AWWs $(p=0.020)$, ASHA $(p=0.058)$ and ANM $(p=0.018)$ showing statistically significant improvement. Only a few of the respondents gave some suggestion for improvement of the sessions. These were the educated respondents which supports the fact that empowerment is a must to raise demand for better health services [Table 3].

\subsection{Comparison of service provisions through VHNDs before and after implementation of different interventions}

Abdominal examination for foetal assessment for size, presentation, lie, foetal heart beat etc and to assess if there is any cephalo-pelvic disproportion; improved from $50.7 \%$ to $58.1 \%$ level. Blood pressure measurement improved from $75.4 \%$ to 87.1\%. Post natal check-up showed huge improvement from $41.7 \%$ to $90.9 \%$ level. Contraceptive use amongst lactating mother also improved from $22.2 \%$ to $45.5 \%$ level. Birth registration improved from $73.9 \%$ to $90 \%$. But child immunization

Table 1 - Comparison of type of respondents (clients) for exit interview in before and after training period.

\begin{tabular}{lrcc}
$\begin{array}{l}\text { Type of } \\
\text { client }\end{array}$ & $\begin{array}{c}\text { Pregnant } \\
\text { women }\end{array}$ & $\begin{array}{c}\text { Lactating mother } \\
\text { with children } \\
\text { below 6 months }\end{array}$ & $\begin{array}{c}\text { Children between } \\
6 \text { months and } \\
5 \text { years }\end{array}$ \\
\hline Before & $70(39.1 \%)$ & $67(37.4 \%)$ & $42(23.5 \%)$ \\
After & $33(44.6 \%)$ & $23(31.1 \%)$ & $18(24.3 \%)$ \\
Total & $103(40.7 \%)$ & $90(35.6 \%)$ & $60(23.7 \%)$ \\
\hline
\end{tabular}

(less than 6 months) dropped from 100\% to 95.2\%, which might be a temporary fluctuation. IFA tablet supply showed slight improvement from $19.5 \%$ to $22.2 \%$ level, but as anaemia is rampant there is a need to improve it further. Vitamin A supplementation for prevention of night blindness and other vitamin A deficiency disorders improved from $89.7 \%$ to $94.4 \%$. Child immunization (6 months-5 years) improved from $90 \%$ to $100 \%$. There was a statistically significant difference in IFA administration, deworming, nutrition and health education and counselling for specific problems [Table 4].

\section{Discussion}

Response rate in exit interview is good. More and more AWCs (Outreach) were being used for conducting VHND sessions, which is the ideal place to conduct VHND indicating better reach of unreached population and improving the accessibility of services. The AWC is identified as the hub for service provision in the RCH-II, NRHM, and also as a platform for intersectoral convergence. Satisfaction level with the quality and behavious of service provider was very good from the community perspective as evident from exit interview finding. The satisfaction level also showed improvement after capacity building of frontline workers in the village like ASHAs, PRI members, AWWs and ANMs. Since the VHNDs are held at a site very close to their habitation, the villagers do not have to spend money or time on travel. The village health and sanitation committee (VHSC) comprising the ASHA, the AWW, the ANM, and the PRI representatives, if fully involved in organizing the event, can bring about changes in the way that people perceive health and health care practices as found in the current study. VHND is the platform for ensuring Maternal Health, Child Health, Family Planning, Nutrition, RTI/ STI services, Sanitation, Communicable Diseases, etc. There is an important role to be played on the front of nutrition, personal hygiene, sanitation, potable drinking water and a good social and behaviour change communication strategy implemented through VHND has potential to improve. In the past maternal and child health services were rather fragmented and provided piece meal by different agencies and service providers. A good convergence model keeping in view the equity issue in micro-planning has potential to reach the unreached. But routine examination of urine for albumin and sugar did not document any evidence of change in our study. Therefore there is a need to give more focus on availability and utilization of routine laboratory investigation at VHND sites.

The key to health lies largely in the environment; in fact much of ill health can be traced to adverse environmental factors such as water pollution, soil pollution, air pollution, poor housing conditions etc. Communication is part of our normal relationship with other people. Communication and education are interwoven strategies to enhance learning for healthful living. An estimated 2.5 billion people (more than $35 \%$ of the world's population) lack access to adequate sanitation. ${ }^{5}$ Water, sanitation and hygiene has the potential to prevent atleast $9.1 \%$ of the global disease burden and $6.3 \%$ of all deaths. ${ }^{6}$ The state of water, sanitation and hygiene reflects the health of a nation and this is particularly relevant in a country like India where $68.84 \%$ of the population resides in 
Table 2 - Comparisons of client satisfaction level with the quality \& behaviour of services provided by service providers during before and after training assessment period.

\begin{tabular}{|c|c|c|c|c|c|c|}
\hline Variable & Period & Not satisfied & Moderately satisfied & Highly satisfied & Chi-square & $p$-Value \\
\hline \multirow[t]{2}{*}{ Satisfied with the quality of services } & Before & $6(3.4 \%)$ & 85 (47.5\%) & $88(49.2 \%)$ & 0.829 & 0.661 \\
\hline & After & $1(1.4 \%)$ & $37(50.0 \%)$ & $36(48.6 \%)$ & & \\
\hline \multirow{2}{*}{$\begin{array}{l}\text { Satisfied with the behaviour of } \\
\text { service provider }\end{array}$} & Before & $5(2.8 \%)$ & 76 (42.5\%) & $98(54.7 \%)$ & 6.651 & 0.036 \\
\hline & After & 0 & $78(52.3 \%)$ & $71(47.7 \%)$ & & \\
\hline
\end{tabular}

Table 3 - Comparison of level of satisfaction during before and after training program amongst different categories of frontline workers.

\begin{tabular}{|c|c|c|c|c|c|}
\hline Service provider & Level of satisfaction & Before & After & Chi-square & $p$-Value \\
\hline \multirow[t]{3}{*}{ AWW } & Not satisfied & $11(6.3 \%)$ & $5(3.4 \%)$ & 7.850 & 0.020 \\
\hline & Moderately satisfied & 75 (43.1\%) & $46(30.9 \%)$ & & \\
\hline & Highly satisfied & $88(50.6 \%)$ & $98(65.8 \%)$ & & \\
\hline \multirow[t]{3}{*}{ ANM } & Not satisfied & $3(1.7 \%)$ & 0 & 8.003 & 0.018 \\
\hline & Moderately satisfied & 75 (42.4\%) & 45 (30.2\%) & & \\
\hline & Highly satisfied & 99 (55.9\%) & $104(69.8)$ & & \\
\hline \multirow[t]{3}{*}{ ASHA } & Not satisfied & $4(2.3 \%)$ & 0 & 5.700 & 0.058 \\
\hline & Moderately satisfied & $65(37.6 \%)$ & $69(46.3 \%)$ & & \\
\hline & Highly satisfied & $104(60.1 \%)$ & $80(53.7 \%)$ & & \\
\hline
\end{tabular}

rural areas. ${ }^{7}$ The definition of primary health care embodied terms such as "self-reliance" and "self-determination" and full participation of the community was considered among the prerequisites of the approach. Participation of people in the planning and implementation process was considered both as a right and a duty. ${ }^{8}$

Comparison of proportion of infants receiving various services during pre and post training period on VHND celebration showed improvement in service provision with supply of iron folic acid (IFA) tablets, deworming, tetanus toxoid (TT) vaccine administration, weight recording, nutrition and health education, growth monitoring for children, vitamin A supplementation and counselling for resolving any specific problem. The Government of India launched the National Rural Health Mission (NRHM) in April 2005. ${ }^{9}$ The Village Health Sanitation and Nutrition Committee (VHSNC, earlier known as Village Health and Sanitation Committee) is one of the major initiatives under NRHM to decentralize and empower local people to achieve NRHM goal. VHSNC comprises of village level health workers, representative from Panchayat Raj Institution

Table 4 - Comparison of respondents receiving various services during VHND sessions during before and after training assessment period.

\begin{tabular}{|c|c|c|c|c|c|c|c|}
\hline \multirow[t]{2}{*}{ Variables } & \multirow{2}{*}{$\begin{array}{l}\text { Respondents } \\
\text { eligible for service }\end{array}$} & \multicolumn{2}{|c|}{ Before } & \multicolumn{2}{|c|}{ After } & \multirow[t]{2}{*}{ Chi-square } & \multirow[t]{2}{*}{$p$-Value } \\
\hline & & Total & $N(\%)$ & Total & $N(\%)$ & & \\
\hline Abdominal check-up & 100 & 69 & 35 (50.7\%) & 31 & $18(58.1 \%)$ & 0.463 & 0.322 \\
\hline BP measured & 100 & 69 & $52(75.4 \%)$ & 31 & 27 (87.1\%) & 1.775 & 0.142 \\
\hline Urine test & 100 & 69 & $26(37.7 \%)$ & 31 & $8(25.8 \%)$ & 1.344 & 0.246 \\
\hline PNC check-up & 82 & 60 & 25 (41.7\%) & 22 & $20(90.9 \%)$ & 15.763 & 0.000 \\
\hline Contraceptives & 85 & 63 & $14(22.2 \%)$ & 22 & $10(45.5 \%)$ & 4.343 & 0.037 \\
\hline Birth registration & 66 & 46 & $34(73.9 \%)$ & 20 & $18(90.0 \%)$ & 2.158 & 0.197 \\
\hline Child immunization (<6 month) & 87 & 65 & $65(100 \%)$ & 22 & $21(95.2 \%)$ & 2.989 & 0.253 \\
\hline IFA tablets received & 59 & 41 & $8(19.5 \%)$ & 18 & $4(22.2 \%)$ & 0.057 & 1.000 \\
\hline Vitamin A supplementation & 57 & 39 & $35(89.7 \%)$ & 18 & $17(94.4 \%)$ & 0.34 & 1.000 \\
\hline Child immunization (6months -5 years) & 58 & 40 & $36(90.0 \%)$ & 18 & $18(100 \%)$ & 1.933 & 0.164 \\
\hline Iron folic acid tablets received & 232 & 162 & $67(41.4 \%)$ & 70 & $41(58.6 \%)$ & 5.821 & 0.016 \\
\hline Deworming tablets received & 244 & 172 & $16(9.3 \%)$ & 72 & $25(34.7 \%)$ & 23.459 & 0.000 \\
\hline TT vaccine received & 90 & 62 & $53(85.5 \%)$ & 28 & $24(85.7 \%)$ & 0.001 & 1.000 \\
\hline Weight recording in pregnant mothers & 95 & 65 & $57(87.7 \%)$ & 30 & $27(90.0 \%)$ & 0.107 & 0.521 \\
\hline Nutrition and health education & 249 & 177 & $114(64.4 \%)$ & 72 & $66(91.7 \%)$ & 18.986 & 0.000 \\
\hline Growth monitoring in children & 148 & 107 & $90(84.1 \%)$ & 41 & $39(95.1 \%)$ & 3.211 & 0.058 \\
\hline Vitamin A supplementation & 57 & 39 & $35(89.7 \%)$ & 18 & $17(94.4 \%)$ & 0.340 & 0.491 \\
\hline Counselling for resolving any specific problem & 224 & 162 & $41(25.3 \%)$ & 62 & $27(43.5 \%)$ & 7.056 & 0.008 \\
\hline
\end{tabular}


(PRI) and representatives of various $\mathrm{CBO}$ including groups who are marginalised. ${ }^{10}$ The roles of VHSNC include development of the village health plan, monitoring of health activities in the village and having a comprehensive understanding of health related activities. Untied fund is also made available to VHSNC for various health activities including IEC, household survey, preparation of health register, organization of Village Health and Nutrition Day etc. meetings at the village level. Limited studies had been conducted to assess the VHSNC in India. Earlier studies conducted to assess VHSNC indicated that formation of committees and fund utilization was not according to guidelines and there were irregularities in conduction of meetings. ${ }^{11}$ In one study most of the members were neither aware about their membership in VHSNC nor about the use of Village Health Fund (VHF). ${ }^{12}$ Another study revealed that some states did not have bank accounts. ${ }^{12,13}$ However, there have been some studies that show effective functioning of VHSNCs. ${ }^{13,14}$ According to results of exit interview findings, majority of the clients were moderately or highly satisfied with all categories of service providers, which showed improvement after capacity building of VHSNC committee members.

Our study focuses the need and usefulness to do periodic sensitization to update the availability of service provision to VHSNC committee members. There should be uninterrupted supply chain for vaccine, medicines and other logistics. Special focus needs to be given for special areas like riverine areas to improve outcome indicators like reduction of maternal and infant mortality. Strengthening of routine investigation facilities likes haemoglobin testing and urine for albumin and sugar needs to be done in all VHNDs for screening for anaemia, preeclampsia and gestational diabetes mellitus early for appropriate care. There is a need to have better delivery of counselling services for nutrition and family planning, IMNCI, awareness regarding water and sanitation through VHND in an integrated manner. Better involvement of PRI members with good leadership development amongst them has the potential to further improve the situation. There is a need to strengthen monitoring and supervision activities for hand holding mentoring and on site correction of the performance of the health care providers, as it is found effective tool for improved performance in our study. Innovative IEC/BCC may improve the accessibility and utilization by improving the adherence and compliance of different services provided by frontline workers. The pre and post training assessments of VHND sessions were not conducted at the same sites and amongst same clients, therefore minor deviation could be expected, which can be considered as a limitation of the study.

\section{Conclusion}

Improvement in service provision and client satisfaction level could be documented in most of the areas of health, nutrition, water and sanitation and communication following capacity building and intensive monitoring and supervision. But there are many areas requiring further strengthening like availability of drugs and other logistics, prevention of communicable diseases mainly TB, family planning, counselling, growth monitoring, care during post natal period, water and sanitation facilities etc. There is a need to have more involvement of Panchayat members. Therefore motivating them for better participation is essential.

\section{Conflicts of interest}

All authors have none to declare.

\section{R E F E R E N C E S}

1. Vistaar Project: Technical Assistance to Government of Jharkhand on Maternal and Child Nutrition and New Born Care in Koderma, Sahibganj and Godda Districts, Jharkhand. Quarterly Progress Report. October-November 2009.

2. Revised Guidelines for Conducting Village Health and Nutrition Day. Office of the Mission Director, National Rural Health Mission, Guwahati. [Online] [cited 2011 May 20]. Available from: URL: http://www.nrhmassam.in/pdf/revised_ guidelines_for_conducting_health_and_nutrition_day_july 092009_.pdf.

3. Costello A, Osrin D, Manandhar D. Reducing maternal and neonatal mortality in the poorest communities. BMj; 329: 1166-1168.

4. Immunization, Supportive Supervision, Micro Plan \& VHND Monitoring and Tool. Norway India Partnership Initiative Madhya Pradesh. [Online]. [cited 2011 May 22]. Available from: URL: http://mpnipi.org/Immunization.html.

5. World Health Organization and UNICEF. Progress on Drinking Water and Sanitation: 2013 Update. United States: WHO/ UNICEF Joint Monitoring Programme for Water Supply and Sanitation; 2013.

6. Pruss-Ustun A, Bos R, Gore F, Bartram J. Safer Water, Better Health: Costs, Benefits and Sustainability of Interventions to Protect and Promote Health. Geneva: World Health Organization; 2008.

7. Govt. of India (2012), Census 2011. Provisional Population Report, Office of the Registrar General and Census Commissioner India, Ministry of Home Affairs. March 31st, 2011.

8. Tatar ha. Community participation in health care: the Turkish case. Soc Sci Med. 1996;42(11):1493-1500.

9. In: An Assessment of Utilization of Untied Fund provided under NRHM in UP. New Delhi: National Institute of Family Welfare; 2008-09 Available from: In: http://www.mohfw.nic.in.

10. Prasad V. An Assessment of the Status of VHSNCs in Bihar, Chhattisgarh, Jharkhand and Orissa. Public Health Resource Network; March 2008 Accessed 02.08.13. Available from: In: www.shsrc.org.

11. In: NHRM's Common Review Mission 2nd. 2008 Accessed 02.08.13. Available from: In: http://www.mohfw.nic.in.

12. Why some water and sanitation committees are better than others. A study in Karnataka and Uttar Pradesh Water and sanitation program, South Asia: Accessed 02.08.13. Available from: http://www.wsp.org.

13. National Rural Health Miss-ion 2005-2012. Mission Document. Accessed 02.08.13. Available from: http://www.mohfw.nic. in/NRHM/Documents/Mission_Document.pdf.

14. In: NRHM Framework for Implementation. 2005-2012 Accessed 02.08.13. Available from: In: http://www.mohfw.nic.in. 